\title{
EXPERIMENTAL RESEARCH OF MASS TRANSFER IN A STABILIZED FOAM LAYER
}

\author{
Viktor Moiseev ${ }^{l}$, Eugenia Manoilo ${ }^{2}$, Oleg Khukhryanskiy ${ }^{3,4}$, Kalif Repko $^{5 凶}$ \\ ${ }^{1}$ Department of Chemical Techniques and Industrial Ecology, National Technical University «Kharkiv Polytechnic Institute», Kharkiv, \\ Ukraine \\ ${ }^{2}$ Department of Chemical Techniques and Industrial Ecology, National Technical University «Kharkiv Polytechnic Institute», Kharkiv, \\ Ukraine \\ ORCID: https://orcid.org/0000-0002-6538-0580 \\ ${ }^{3}$ Department of Chemical Engineering, Sumy State University, Sumy, Ukraine \\ ${ }^{4}$ UzLITI Engineering, Tashkent, Republic of Uzbekistan \\ ORCID: https://orcid.org/0000-0002-3554-2067 \\ ${ }^{5}$ Department of Chemical Techniques and Industrial Ecology, National Technical University «Kharkiv Polytechnic Institute», Kharkiv, \\ Ukraine \\ ORCID: https://orcid.org/0000-0002-9244-2660 \\ Corresponding author: Viktor Moiseev, e-mail: vmoiseev1209@gmail.com
}

ARTICLE INFO

ABSTRACT

Article history:

Received date 23.09.2021

Accepted date 23.10.2021

Published date 29.10.202

The object of research: mass transfer processes on a combined contact element in a column apparatus.

Section:

Chemical industry

Investigated problem: determination of the regularities of process parameters in the processing of gas-liquid systems in a foam layer, as well as to interpret the obtained experimental data. The problem of processing industrial gas flows is solved by conducting the process in an intensive mode.

DOI

$10.21303 / 2313-8416.2021 .002123$

KEYWORDS

The main scientific results: as a result of the study, the regularities of ammonia absorption were revealed depending on the main parameters of the experiment: gas velocity in the column cross-section, ammonia concentration, free cross-section of the combined contact

industrial gas emissions

cleaning process

mass transfer

foam layer apparatus

foam layer

research of purification processes

stabilization of foam layer

intensive apparatus element, and liquid loads. The process of mass transfer in the gas phase is significantly influenced by hydrodynamic parameters - the gas velocity in the apparatus and the specific load on the liquid, which indirectly affect the height of the liquid layer on the plate and the gas content of the layer.

The area of practical use of the research results: sorption processes for processing gases and liquids in technological processes, absorption of harmful substances in the treatment of gas emissions.

Innovative technological product: new block poppet-nozzle contact device that operates in a stabilized hydrodynamic mode; new ball-shaped weighted nozzle for three-phase foam layer.

Scope of application the innovative technological product: technological processes in the treatment of gas emissions or technological gases.

(c) The Author(s) 2021. This is an open access article under the Creative Commons CC BY license

\section{Introduction}

\section{1. The object of research}

The object of research is mass transfer processes on a combined contact element in a column apparatus.

\section{2. Problem description}

In conditions of significant anthropogenic pressure on the environment the investigation for the most effective and economical methods of cleaning industrial emissions is relevant. Cleaning methods and equipment developed should take into account the possibility of working in a wide range of operating conditions. To reduce energy consumption in systems for capturing harmful and toxic substances, it is necessary to reduce hydraulic resistance while maintaining high efficiency in cleaning gas flows.

Given the contradictory requirements for equipment and despite the large number of existing devices for mass transfer processes, the development of new high-intensity and efficient equipment is of considerable interest to environmental technologies in many industries [1]. 
A common method of cleaning gas streams is absorption methods for absorbing harmful components from exhaust industrial gases. In this case, either the process of physical absorption occurs, or the absorbent enters into chemical interaction with the absorbed component [2].

\subsection{Suggested solution to the problem}

Foam mode and foam devices of the "classical" type are described in works [3, 4]. Due to its high efficiency, high unit capacity, good operational qualities of their application, they can improve the stages of gas purification for technological and sanitary purposes, increase efficiency and increase the reliability of gas-cleaning equipment [5]. One of the promising areas of intensification of the mass transfer process is the development of apparatuses using a stabilized foam mode of interaction of gas-liquid flows. Previously studied devices with a foam layer [6] were used mainly in technological cycles with significant specific loads on gas and liquid, which led to high energy consumption. At the same time, in systems for cleaning industrial gases from harmful components, which are usually present in low concentrations, it is necessary to ensure a high degree of gas purification with minimal liquid consumption and low spray ratio [7].

One of the promising areas for intensifying the mass transfer process is the development of apparatuses using foam modes of interaction of gas-liquid flows, including in the layer of moving bodies. Compared to traditional plate and nozzle columns foam apparatuses with foam layer stabilization have a number of advantages:

- the ability to operate in a wide range of gas speeds without significantly increasing hydraulic resistance, which is especially important for gas purification processes in conditions with frequently variable flow rates both in the direction of decreasing and increasing;

- almost homogeneous distribution of the liquid phase over the entire cross-section of the device, which leads to an increase in the mass transfer surface;

- high turbulence of gas and liquid flows, which provides high coefficients of heat and mass transfer;

- the possibility of intensifying the operation of existing absorption columns equipped with sinkhole plates by changing the operating mode of the device.

The previously studied foam layer apparatuses were mainly used in technological cycles with significant specific loads on gas and liquid, which led to high energy consumption. At the same time, in industrial gas purification systems from harmful components present, as a rule, in low concentrations, it is necessary to ensure a high degree of gas purification with minimal liquid loads [8].

The aim of research is to obtain the regularities of process parameters in the processing of gas-liquid systems in a foam layer, as well as to analyze and interpret the experimental data.

The problem of processing industrial gas flows is solved by conducting the process in an intensive mode. Industrial implementation of absorption processes in the foam layer and the use of the gas-liquid layer stabilization method significantly expand the scope of application of foam apparatuses and opens up new opportunities for intensifying technological processes while simultaneously creating low-waste technologies. And the use of modern designs of regular nozzles as stabilizers allows to modernize the existing absorption devices.

\section{Materials and Methods}

For these purposes, a new design of the stabilizer with a large free volume was developed. The advantage of the proposed design is the transition to a structured foam mode of operation at relatively low gas speeds, as well as a developed phase contact surface. The cellular structure from which the stabilizer is made makes it possible to achieve increased values of mass transfer coefficients due to the effect of film formation in small cells. The structure has high porosity and low hydraulic support. Depending on the selection of material, the structure may have different wettability.

The new structures are simple and have a relatively low cost, which allows them to be effectively used in the processes of cleaning waste gases in various industries, in cooling towers of recycled water supply systems, in a number of other processes of heat and mass transfer, including by upgrading existing installations. 
Hydrodynamic modes of motion of droplets and films in the gas-liquid layer of foam apparatuses differ sharply from traditional ones and significantly affect the efficiency of mass transfer processes. To calculate the mass transfer coefficient in the gas phase in an apparatus with a foam layer for the absorption of fluoride gases by various absorbers the following general equation was proposed [9]:

$$
\beta_{g}=A \cdot w_{g}^{1.1} L^{0.13} H^{0.43} d_{n}^{-0.3} \rho_{n} \cdot e^{1.8 S_{0}}
$$

In which the constant $A$ is determined experimentally for each gas and absorber system. The efficiency or degree of absorption is determined by the equation [9]:

$$
\beta_{i}=w_{g} \ln \frac{c_{1}}{c_{2}} \text {. }
$$

The final concentration $c_{2}$ is determined at a known initial concentration of the absorbed gas $c_{1}$. The effectiveness or degree of absorption is calculated as

$$
\eta=\frac{c_{1}-c_{2}}{c_{1}} 100 \%
$$

\section{1. Experimental procedures}

To study mass transfer in the gas phase $\beta_{g}$, ammonia was chosen as the absorbed component, and water was chosen as the absorber phase. Air was considered an inert gas that does not dissolve in water. The research was taken on a laboratory installation, which is shown in Fig. $\mathbf{1 .}$

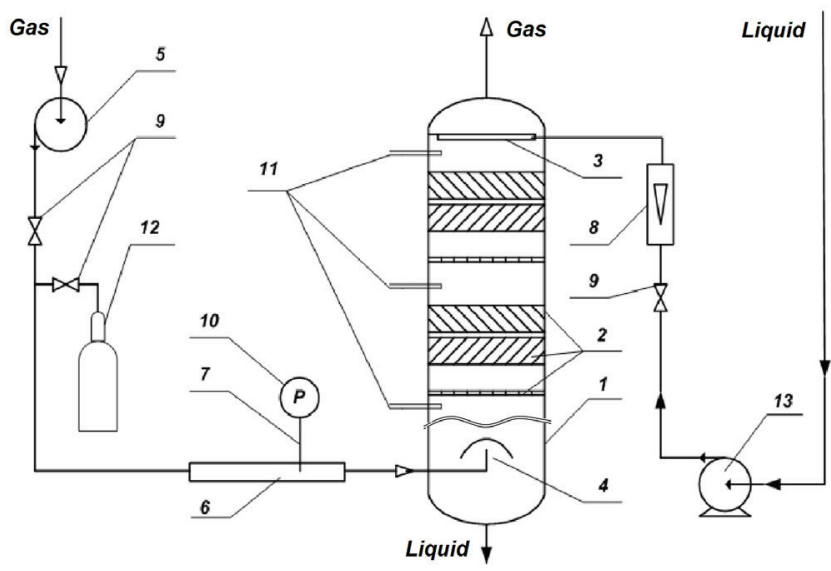

Fig. 1. Scheme of a laboratory installation for studying mass transfer in the gas phase:

1 - column; 2 - combined contact element Unit; 3 - liquid distributor; 4 - gas distributor; 5 - gas blower; 6 - measuring pipe; 7 - pitot tube; 8 - rotameter; 9 - valves; 10 -diffmanometers; 11 - samplers; 12 - ammonia cylinder, 13 - pump

Inside the column 1 there is a combined contact unit 2. An air - ammonia mixture was supplied from the bottom of the column, which was obtained by mixing ammonia from the cylinder 12 with air pumped by a gas blower 5. Irrigation water was supplied to the top of the column from the water supply system through a liquid distributor. Low-concentration ammonia water formed as a result of absorption was discharged into the sewer, and air was discharged into the atmosphere. The flow rates of water and ammonia were regulated by valves 9 and measured by rotameters 8 , respectively.

The ammonia concentration was determined by sampling by titration. The liquid flow rate ranged from 1 to $15 \mathrm{~m}^{3} / \mathrm{m}^{2} \mathrm{~h}$, and the gas velocity ranged from $2-4 \mathrm{~m} / \mathrm{s}$.

The procedure for sampling was carried out as follows: the water supply valve was opened and the required flow rates were set. Then the gas blower was started and the air flow rate corre- 
sponding to the foam mode was set. Open the valve 9 for the supply of ammonia and set its flow rate. After 5 minutes, gas samples were taken at the bottom and top of the column and a liquid sample at the bottom of the column. The temperature of the medium was $20^{\circ} \mathrm{C}$. Then the sampling was repeated again. At the end of the measurement, the ammonia supply was closed, the gas blower was turned off, and the water was turned off.

The ammonia content in the sample was determined using phenolphthalein, sulfuric acid solution, and sodium hydroxide solution. The loads and amount of absorbed ammonia were determined by the material balance of absorption.

Efficient operation of mass transfer equipment is achieved with a specific combination of the values of the mass transfer coefficient $K$ and the efficiency factor $\eta$, which characterizes the efficiency of the mass transfer process.

Between $\eta$ and $K$ such a relationship was specified as [10]:

$$
\eta=\frac{2 K}{2 \omega_{g}+K}
$$

Mass transfer in the gas phase was studied on a stand with a column of $0.24 \mathrm{~m}$ under conditions of ammonia absorption by water. Ammonia absorption was carried out at a gas velocity $=2-4 \mathrm{~m} / \mathrm{s}$ using a foam layer stabilizer of certain optimal parameters. The stabilizer was installed above the hole plate at a height of $0.1-0.12 \mathrm{~m}$.

As a result of the study, the regularities of ammonia absorption were revealed depending on the main parameters of the experiment: gas velocity in the column cross-section, ammonia concentration, free cross-section of the combined contact element, and liquid loads.

\section{Results}

When studying the absorption of ammonia (Fig. 2) it was found that the efficiency of the device somewhat depends on the change in the gas velocity. However, it can be observed that the efficiency with the use of a stabilizer is greater than without it and is noticeably greater when using a stabilizer with a plate with a smaller free cross-section and with plate holes $d_{e}=0.012 \mathrm{~m}$.

This can be explained by the fact that plates with a larger free cross-section contribute to a larger liquid failure, and sufficiently large holes and a moderately low free cross-section create a greater height of the foam layer, and thus the mass transfer surface increases. This fact is confirmed by an increase in the intensity of the absorption process for such a combination of contact block elements.

After analyzing the obtained experimental data, they are shown in Fig. 3 it can be saying that an increase in the free cross-sectional area leads to a decrease in the efficiency of the contact element. Fig. 4 shows that the irrigation density in the combined contact element affects absorption only up to $8-10 \mathrm{~m}^{3} / \mathrm{m}^{2} \mathrm{~h}$, then its effect stabilizes and is insignificant.

When using a stabilizer, a noticeable increase in the efficiency in the combined contact element was observed depending on the concentration of ammonia compared to the experiment without using a stabilizer (Fig. 5). The efficiency of the combined contact element increases by 15-17 percent, all other things being equal, when using a stabilizer with a smaller free cross - section of hole plates. This is consistent with the works of the authors [10], which makes it possible to use well-known methods for calculating the required number of steps to achieve a given process efficiency.

So, after analyzing Fig. 6 it is possible to say that increasing liquid irrigation increases the mass transfer coefficient. When the free cross-sectional area of the hole plate increases (Fig. 7) there was a decrease in ammonia absorption. This is due to a decrease in the amount of liquid in the combined contact element, its failure to lower contact stages, an unstable foam layer, and a decrease in the phase contact surface.

When the diameter of the holes increases (Fig. 8) in the plate, there was also a decrease in the mass transfer coefficient due to the above factors. The mass transfer coefficient is significantly influenced by the gas velocity, as can be seen from the results shown in Fig. 9. 


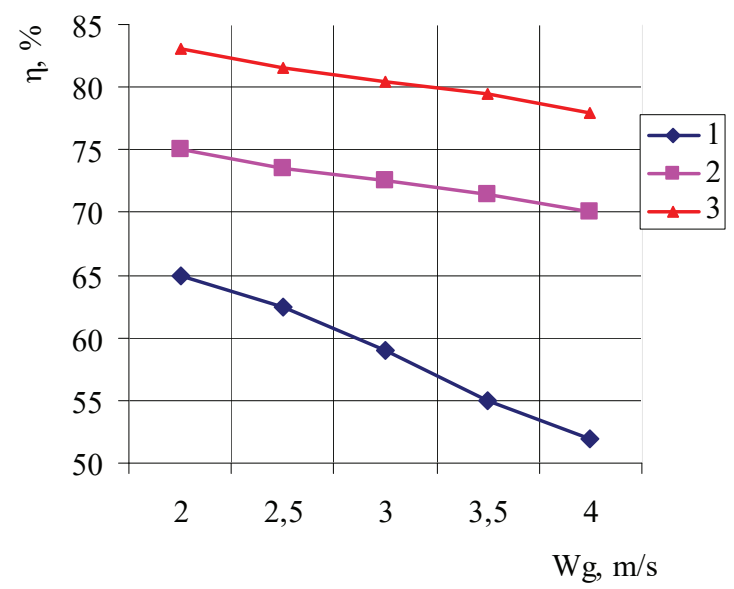

Fig. 2. Dependence of the efficiency for the ammonia-water system in a combined contact element on the gas velocity: $L_{0}=5 \mathrm{~m}^{3} / \mathrm{m}^{2} \times \mathrm{h} ; 1-d_{e}=0.02 \mathrm{~m}, S_{0}=0.383 \mathrm{~m}^{2} / \mathrm{m}^{2}-$ without stabilizer;

$2-d_{e}=0.015 \mathrm{~m}, S_{0}=0.217 \mathrm{~m}^{2} / \mathrm{m}^{2}-$ with stabilizer; $3-d_{e}=0.012 \mathrm{~m}, S_{0}=0.137 \mathrm{~m}^{2} / \mathrm{m}^{2}-$ with stabilizer

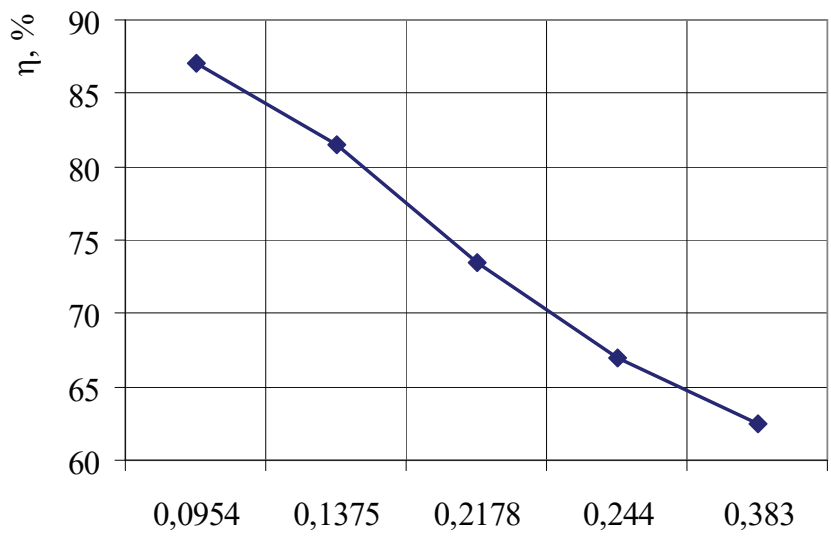

S0

Fig. 3. Dependence of the efficiency in the ammonia-water system in a combined contact element on the free cross-section of the hole plate $S_{0}, \mathrm{~m}^{2} / \mathrm{m}^{2}$ :

$L_{0}=5 \mathrm{~m}^{3} / \mathrm{m}^{2} \times \mathrm{h} ; W_{g}=2.5 \mathrm{~m} / \mathrm{s}, C_{\mathrm{NH} 3}=2 \%$

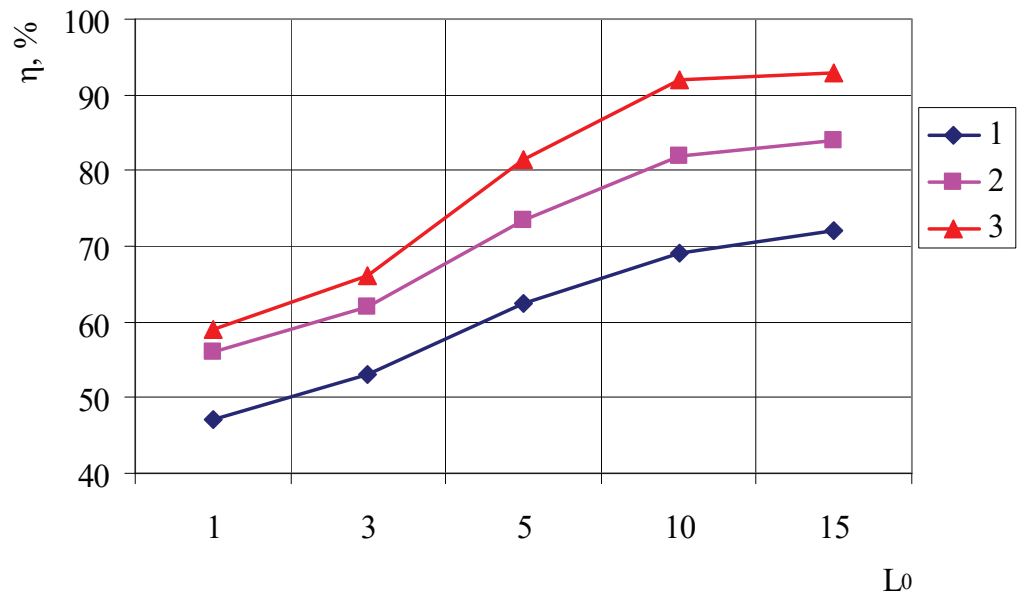

Fig. 4. Dependence of the efficiency factor for the ammonia-water system in a combined contact element on the irrigation density $\mathrm{L}_{0}, \mathrm{~m}^{3} / \mathrm{m}^{2} \mathrm{~h}: W_{g}=2,5 \mathrm{~m} / \mathrm{s}, C_{\mathrm{NH} 3}=2 \%: 1-d_{e}=0.02 \mathrm{~m}$,

$S_{0}=0.383 \mathrm{~m}^{2} / \mathrm{m}^{2}$ - without stabilizer; $2-d_{e}=0.015 \mathrm{~m}, S_{0}=0.217 \mathrm{~m}^{2} / \mathrm{m}^{2}-$ with stabilizer; $3-d_{e}=0.012 \mathrm{~m}$, $S_{0}=0.137 \mathrm{~m}^{2} / \mathrm{m}^{2}-$ with stabilizer 


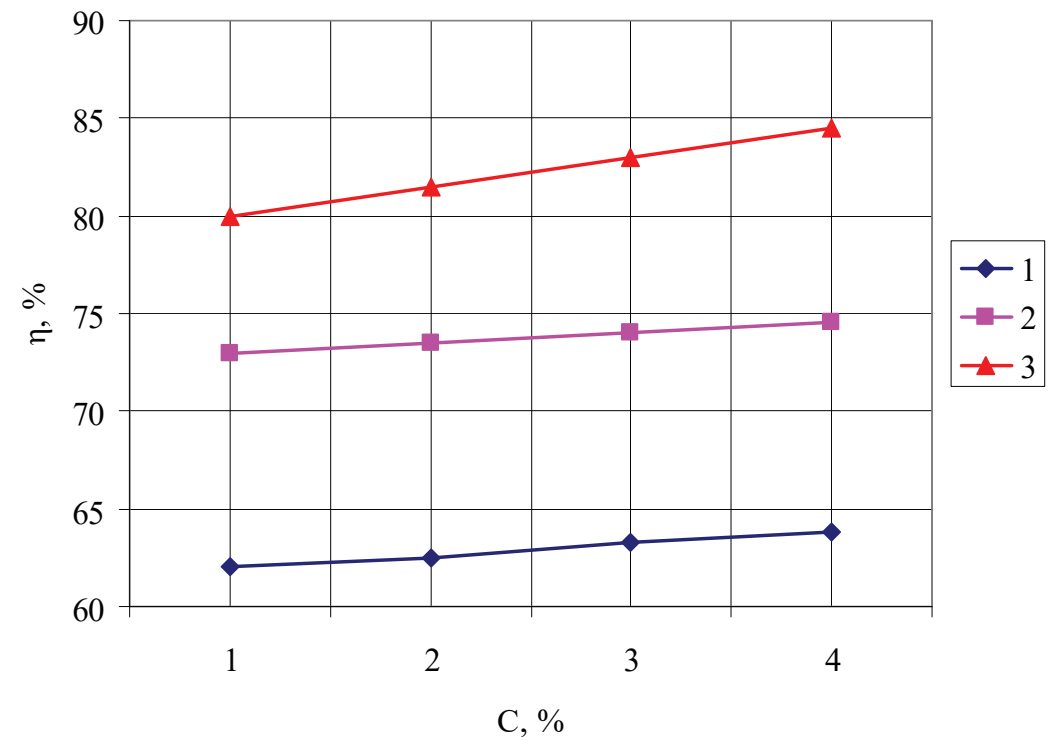

Fig. 5. Dependence of the efficiency factor for the ammonia-water system in a combined contact element on the initial concentration of ammonia: $W_{g}=2.5 \mathrm{~m} / \mathrm{s}, L_{0}=5 \mathrm{~m}^{3} / \mathrm{m}^{2} \times \mathrm{h}: 1-d_{e}=0.02 \mathrm{~m}$, $S_{0}=0.383 \mathrm{~m}^{2} / \mathrm{m}^{2}$ - without stabilizer; $2-d_{e}=0.015 \mathrm{~m}, S_{0}=0.217 \mathrm{~m}^{2} / \mathrm{m}^{2}-$ with stabilizer; $3-d_{e}=0.012 \mathrm{~m}, S_{0}=0.137 \mathrm{~m}^{2} / \mathrm{m}^{2}-$ with stabilizer

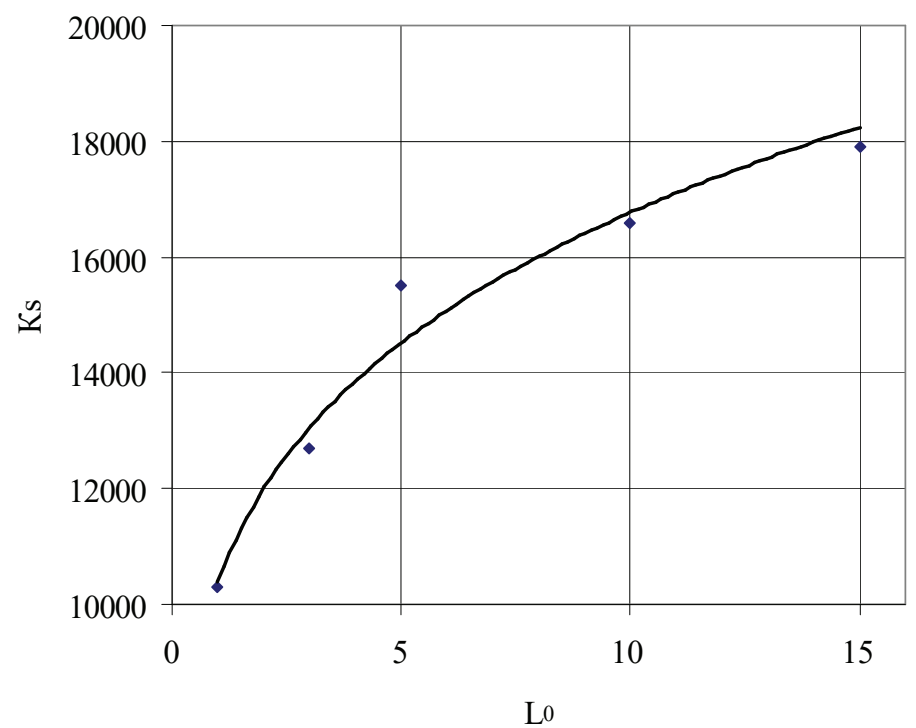

Fig. 6. Dependence of the mass transfer coefficient $(\mathrm{m} / \mathrm{h})$ assigned to the plate area on the irrigation density $\left(\mathrm{m}^{3} / \mathrm{m}^{2} \mathrm{~h}\right)$. Ammonia - water system: $d_{e}=0.012 \mathrm{~m}$,

$$
S_{0}=0.137 \mathrm{~m}^{2} / \mathrm{m}^{2}-\text { with stabilizer, } W_{g}=2.5 \mathrm{~m} / \mathrm{s}
$$

After processing the experimental data, empirical dependences were obtained for calculating the mass transfer coefficient in the gas phase $\mathrm{m} / \mathrm{h}$ :

$$
K_{s}=1.3 \cdot 10^{3} W_{g}^{1.5} L_{0}^{0.17} d_{e}^{0.38} S_{0}^{-0.77}
$$

and when determining efficiency, $\%$ :

$$
\eta=0.170 \cdot 10^{3} W_{g}^{-1.7} L_{0}^{0.35} d_{e}^{-0.3} S_{0}^{-0.52}
$$


Formulas are applied in the following boundaries: $W_{g}=2-4 \mathrm{~m} / \mathrm{s}, L_{0}=3-15 \mathrm{~m}^{3} / \mathrm{m}^{2} \mathrm{~h}, S_{0}=0.1-$ $0.4 \mathrm{~m}^{2} / \mathrm{m}^{2}, d_{e}=0.01-0.02 \mathrm{~m}$.

The error of calculations based on these equations did not exceed $15 \%$.

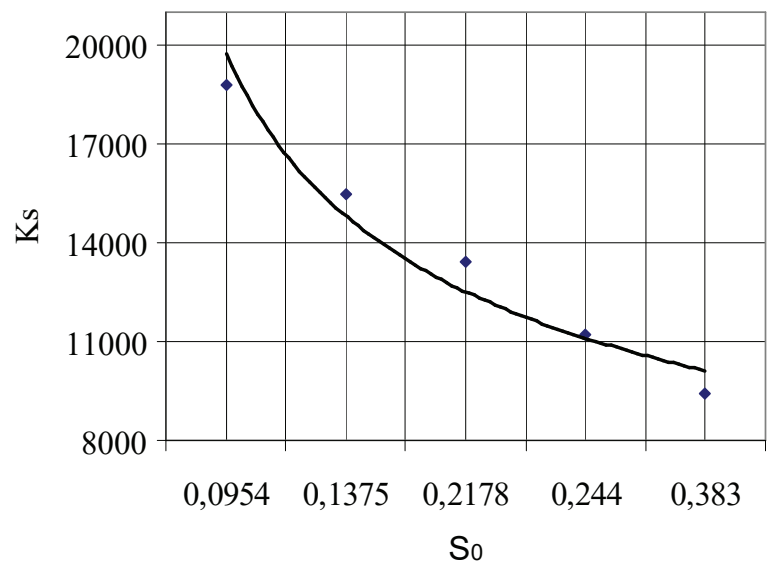

Fig. 7. Dependence of the mass transfer coefficient $(\mathrm{m} / \mathrm{h})$ assigned to the area of the plate on the free cross-section of the hole plate $\left(\mathrm{m}^{2} / \mathrm{m}^{2}\right)$. Ammonia - water system: $L_{0}=5 \mathrm{~m}^{3} / \mathrm{m}^{2} \times \mathrm{h}, W_{g}=2.5 \mathrm{~m} / \mathrm{s}$

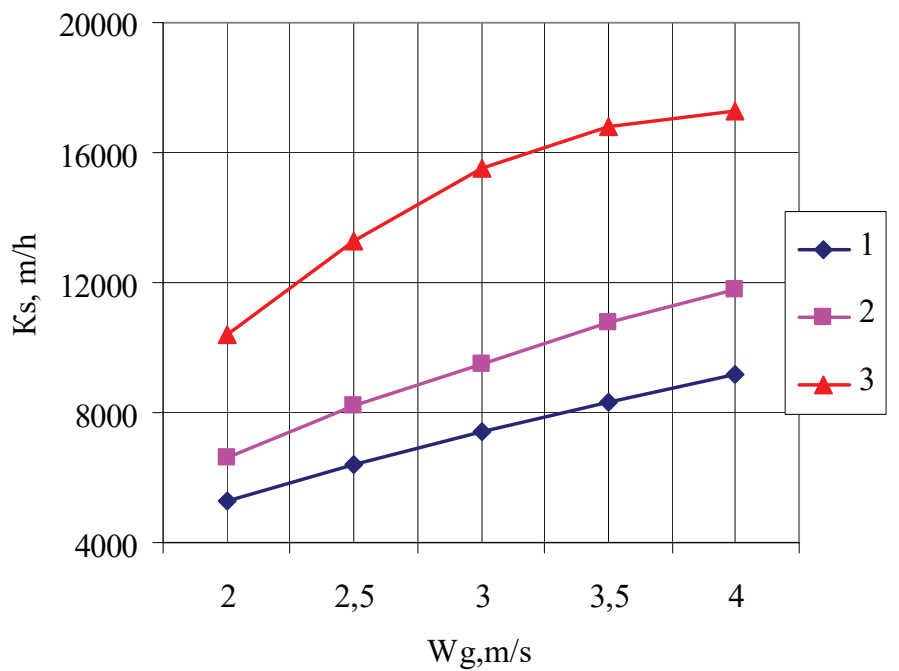

Fig. 8. Dependence of the mass transfer coefficient of the combined contact element on the gas velocity. Ammonia - water system: $L_{0}=5 \mathrm{~m}^{3} / \mathrm{m}^{2} \times \mathrm{h} ; 1-d_{e}=0.02 \mathrm{~m}, S_{0}=0,383 \mathrm{~m}^{2} / \mathrm{m}^{2}-$ without stabilizer; $2-d_{e}=0.015 \mathrm{~m}, S_{0}=0.217 \mathrm{~m}^{2} / \mathrm{m}^{2}-$ with stabilizer; $3-d_{e}=0.012 \mathrm{~m}$,

$$
S_{0}=0.137 \mathrm{~m}^{2} / \mathrm{m}^{2}-\text { with stabilizer }
$$

When deriving the calculated criterion equations for ammonia absorption, the dependence of $K_{s}=f(H)$ represent it as a monomial $[9,10]$ :

$$
K_{s}=n(H)^{m}
$$

As a result of processing experimental data, an equation was obtained for determining the mass transfer coefficient in the gas phase $\mathrm{K}_{\mathrm{s}}, \mathrm{m} / \mathrm{h}$ :

$$
K_{s}=11,145 W_{g} H^{0.33}
$$

As can be seen from Fig. 8 the gas velocity has a significant effect on the height of the gas-liquid layer and the mass transfer coefficient in the combined contact element. The deviation of the experimental data from the calculated ones according to (8) did not exceed $\pm 15 \%$. 


\section{Discussion}

Therefore, the efficiency of mass transfer in a combined contact element operating in a stable foam mode confirms that the selected design of the elements causes intensive mixing of interacting phases, restraint of gas content in a certain range and an increase in the size of the contact surface of the phases and the rate of their renewal.

The noticeable difference in the form of the equations, their validity only for relatively narrow ranges of operating conditions, does not allow to recommend the use of these dependencies for calculating industrial or pilot installations operating in other hydrodynamic modes, or on other interacting systems $[11,12]$. Therefore, when reconstructing existing and designing new gas emission treatment equipment, additional experimental studies are needed to identify patterns of the cleaning process.

It is possible to use the proposed design using a three-phase foam layer with a weighted nozzle for further intensification of absorption apparatuses. Previously, it was suggested that the use of mesh materials for the manufacture of nozzle bodies is promising, then it is necessary to emphasize the peculiarity of the operation of devices with such nozzles [13].

In devices with ball nozzles, gas passes between the channels formed by the nozzle bodies, and liquid in the form of films and drops flows down the surface of the balls. In the case of a mesh nozzle, the interaction of gas with liquid occurs not only on the surface of the nozzle, but also inside its volume. Therefore, the mechanism of switching the nozzle to the developed fluidization mode will differ significantly from conventional ball nozzles. Therefore, it is necessary to conduct further studies of the hydrodynamic modes of operation of the device with a mesh nozzle and determine the parameters that affect the speed of transition of the nozzle from one mode to another.

The study of mass transfer in a fluidized bed absorber of an irrigated nozzle is complicated by the fact that the contact surface between the phases can vary significantly depending on hydrodynamic conditions, in particular, on the gas velocity and irrigation density. At the same time, it is difficult to determine the influence of these factors on the contact surface and on the mass transfer coefficient.

When evaluating the efficiency of absorbers with a three-phase layer, mass transfer coefficients (volume and surface) or the number of transfer units are used. The volume mass transfer coefficient refers to a unit of static nozzle volume ( $K_{y}$ coefficient) or a unit of dynamic layer volume ( $K_{a}$ coefficient).

The considered equations show that the determination of the intensity of substance transfer in a layer with a fluidized bed irrigated nozzle does not have firmly established regularities. All equations are empirical and determine the possibility of their application only for the conditions of experiments on the example of which they are derived. This shows that studying the intensity of substance transfer in the fluidized bed layer requires further research.

Thus, the calculation and design of devices with a foam layer and a fluidized bed nozzle is carried out so far only on the basis of experimental data [14-17] obtained on a limited number of interacting systems. Theoretical provisions are not sufficiently developed, so in practice, only the ball nozzle finds the main application in devices with a movable nozzle as the most studied, and other designs remain unclaimed.

The resulting equations in this work are applied in the following boundaries: $W_{g}=2-4 \mathrm{~m} / \mathrm{s}$, $L_{0}=3-15 \mathrm{~m}^{3} / \mathrm{m}^{2} \mathrm{~h}, S_{0}=0.1-0.4 \mathrm{~m}^{2} / \mathrm{m}^{2}, d_{e}=0.01-0.02 \mathrm{~m}$.

\section{Conclusions}

It can be concluded that the process of mass transfer in the gas phase is significantly influenced by hydrodynamic parameters - the gas velocity in the apparatus and the specific load on the liquid, which indirectly affect the height of the liquid layer on the plate and the gas content of the layer, as well as the physical and chemical properties of interacting systems have not been studied. The efficiency of the combined contact element increases by $15-17 \%$, all other things being equal, when using a stabilizer with a smaller free cross - section of hole plates.

The empirical equations for calculating the mass transfer coefficient in the gas phase describes the system with an error probability of no more than $15 \%$.

Analysis of a number of studies shows that a promising direction for intensifying the mass transfer process is the development of devices with a three-phase stabilized fluidized bed of an irrigated nozzle made of mesh materials. For gas purification systems from gaseous components, it is necessary to ensure low loads on the liquid while maintaining a high degree of purification. This can be achieved by using a hole plate with a small or medium free cross-section and a newly developed nozzle and stabilizer. 
The industrial implementation of the gas-liquid layer stabilization method significantly expands the scope of application of foam apparatuses and opens up new opportunities for intensifying technological processes while simultaneously creating low-waste technologies.

\section{Acknowledgment}

All the results of the research were achieved within the projects "Development of structural and technological solutions for the reconstruction of column apparatuses" (State reg. No. 0118U003999).

\section{References}

[1] Fourati, M., Roig, V., Raynal, L. (2012). Experimental study of liquid spreading in structured packings. Chemical Engineering Science, 80, 1-15. doi: http://doi.org/10.1016/j.ces.2012.05.031

[2] Kong, Q. J., Liu, D. Y., Wang, P., Xie, D. Q., Wu, Q., Zhao, X. Y. (2019). Experimental study on the heat and mass transfer characteristics of a counter-flow wet cooling tower with foam ceramic packing. Thermophysics and Aeromechanics, 26 (2), 267-279. doi: http://doi.org/10.1134/s0869864319020100

[3] Pavlenko, A. N., Pecherkin, N. I., Zhukov, V. E., Meski, G., Houghton, P. (2020). Overview of methods to control the liquid distribution in distillation columns with structured packing: Improving separation efficiency. Renewable and Sustainable Energy Reviews, 132, 110092. doi: http://doi.org/10.1016/j.rser.2020.110092

[4] Zbytovský, J., Sommer, T., Zapletal, M., Trejbal, J. (2019). Comparison of various column packing materials efficiency for hydrocarbons and aqueous mixtures. Chemical \& Biochemical Engineering Quarterly, 33 (2), 183-190. doi: http://doi.org/ 10.15255/cabeq.2018.1565

[5] Clavier, R., Chikhi, N., Fichot, F., Quintard, M. (2017). Modeling of inertial multi-phase flows through high permeability porous media: Friction closure laws. International Journal of Multiphase Flow, 91, 243-261. doi: http://doi.org/10.1016/ j.ijmultiphaseflow.2017.02.003

[6] Fourati, M., Roig, V., Raynal, L. (2012). Experimental study of liquid spreading in structured packings. Chemical Engineering Science, 80, 1-15. doi: http://doi.org/10.1016/j.ces.2012.05.031

[7] Kuznetsov, P. V. (2004). Structural parameters of the foam layer on fine-grained countercurrent lattices with a stabilizer. East European Journal of advanced technologies, 4 (10), 84-88.

[8] Moiseev, V., Liaposhchenko, O., Trebuna, P., Manoilo, E., Khukhryanskiy, O. (2020). Properties of Heat and Mass Transfer Processes in the Tubular Grids with the Heat Exchanger as a Stabilizer. Advances in Design, Simulation and Manufacturing II. Springer, 795-804. doi: http://doi.org/10.1007/978-3-030-22365-6_79

[9] Moiseev, V., Manoilo, E., Ponomarova, N., Repko, K., Davydov, D. (2018). Methodology of calculation of construction and hydrodynamic parameters of a foam layer apparatus for mass-transfer processes. Bulletin of the National Technical University «KhPI» Series: New Solutions in Modern Technologies, 16 (1292), 165-176. doi: http://doi.org/10.20998/2413-4295.2018.16.25

[10] Moiseev, V., Liaposhchenko, O., Manoilo, E., Demianenko, M., Khukhryanskiy, O. (2021). Hydrodynamic Parameters of a Combined Contact Device. Advances in Design, Simulation and Manufacturing IV. Springer, 257-267. doi: http://doi.org/ 10.1007/978-3-030-77823-1_26

[11] Perry, D. C., Stevenson, P. (2015). Gas absorption and reaction in a wet pneumatic foam. Chemical Engineering Science, 126, 177-185. doi: http://doi.org/10.1016/j.ces.2014.11.037

[12] Marias, F., Puiggali, J. R., Flamant, G. (2001). Effects of Freeboard Volatile Release During Fluidized Bed Incineration of a Model Waste. Process Safety and Environmental Protection, 79 (4), 244-252. doi: http://doi.org/10.1205/095758201750362280

[13] Moiseev, V., Manoilo, E., Vasyliev, M., Repko, K., Davydov, D. (2017). Processing of gas-liquid systems on tubular gratings with stabilizer of a foam layer. Bulletin of the National Technical University «KhPI» Series: New Solutions in Modern Technologies, 53 (1274), 114-123. doi: http://doi.org/10.20998/2413-4295.2017.53.17

[14] Jang, J., Arastoopour, H. (2014). CFD simulation of a pharmaceutical bubbling bed drying process at three different scales. Powder Technology, 263, 14-25. doi: http://doi.org/10.1016/j.powtec.2014.04.054

[15] Wang, S., Wang, S., Wu, B., Lu, Y., Zhang, K., Chen, H. (2021). Effect of packing structure on anisotropic effective thermal conductivity of thin ceramic pebble bed. Nuclear Engineering and Technology, 53 (7), 2174-2183. doi: http://doi.org/10.1016/j.net.2021.01.013

[16] Flagiello, D., Di Natale, F., Lancia, A., Erto, A. (2020). Characterization of mass transfer coefficients and pressure drops for packed towers with Mellapak 250.X. Chemical Engineering Research and Design, 161, 340-356. doi: http://doi.org/10.1016/ j.cherd.2020.06.031

[17] Clavier, R., Chikhi, N., Fichot, F., Quintard, M. (2017). Modeling of inertial multi-phase flows through high permeability porous media: Friction closure laws. International Journal of Multiphase Flow, 91, 243-261. doi: http://doi.org/10.1016/ j.ijmultiphaseflow.2017.02.003 